NBER WORKING PAPER SERIES

\title{
FINANCIAL LITERACY AMONG THE YOUNG: EVIDENCE AND IMPLICATIONS FOR CONSUMER POLICY
}

\author{
Annamaria Lusardi \\ Olivia S. Mitchell \\ Vilsa Curto \\ Working Paper 15352 \\ http://www.nber.org/papers/w15352
}

\author{
NATIONAL BUREAU OF ECONOMIC RESEARCH \\ 1050 Massachusetts Avenue \\ Cambridge, MA 02138 \\ September 2009
}

\begin{abstract}
The research reported herein was conducted pursuant to a grant from the U.S. Social Security Administration (SSA) to the Michigan Retirement Research Center, funded as part of the Retirement Research Consortium. We also received a generous grant from FINRA Investor Education Foundation. Additional support was provided by the Pension Research Council and Boettner Center at the Wharton School of the University of Pennsylvania. We are very grateful to Dan Black for his help with the data. We would also like to thank Brenda Cude, Anna Paulson, Jack Tatom, and participants in the conference "Improving Financial Literacy and Reshaping Financial Behavior" at the Networks Financial Institute at Indiana State University, Indianapolis, IN, the symposium on "Improving the Effectiveness of Financial Education in the Classroom" at the Take Charge America Institute at the University of Arizona, Tucson, AZ, and the University of Michigan Retirement Research Center research workshop, Ann Arbor, MI, for many helpful suggestions and comments. Hiroaki Matsuura provided excellent research assistance. Opinions and errors are solely those of the authors and not of the institutions with which the authors are affiliated. The views expressed herein are those of the author(s) and do not necessarily reflect the views of the National Bureau of Economic Research.
\end{abstract}

NBER working papers are circulated for discussion and comment purposes. They have not been peerreviewed or been subject to the review by the NBER Board of Directors that accompanies official NBER publications.

(C) 2009 by Annamaria Lusardi, Olivia S. Mitchell, and Vilsa Curto. All rights reserved. Short sections of text, not to exceed two paragraphs, may be quoted without explicit permission provided that full credit, including $\odot$ notice, is given to the source. 
Financial Literacy among the Young: Evidence and Implications for Consumer Policy Annamaria Lusardi, Olivia S. Mitchell, and Vilsa Curto

NBER Working Paper No. 15352

September 2009

JEL No. D91

\section{ABSTRACT}

We examined financial literacy among the young using data from the 1997 National Longitudinal Survey of Youth. We showed that financial literacy is low among the young; fewer than one-third of young adults possess basic knowledge of interest rates, inflation, and risk diversification. Financial literacy is strongly related to sociodemographic characteristics and family financial sophistication. Specifically, a college-educated male whose parents had stocks and retirement savings is about 50 percentage points more likely to know about risk diversification than a female with less than a high school education whose parents were not wealthy. These findings have implications for consumer policy.

\author{
Annamaria Lusardi \\ Department of Economics \\ Dartmouth College \\ Hanover, NH 03755 \\ and NBER \\ a.lusardi@dartmouth.edu \\ Olivia S. Mitchell \\ University of Pennsylvania \\ Wharton School \\ 3620 Locust Walk, St 3000 SH-DH \\ Philadelphia, PA 19104-6302 \\ and NBER \\ mitchelo@wharton.upenn.edu
}

\author{
Vilsa Curto \\ NBER \\ 1050 Massachusetts Avenue \\ Cambridge, MA 02138 \\ vilsa.curto@post.harvard.edu
}




\section{Financial Literacy among the Young: Evidence and Implications for Consumer Policy}

Consumers must confront complicated financial decisions at a young age in today's demanding financial environment, and financial mistakes made early in life can be costly. Young people often find themselves carrying high amounts of student loans or credit card debt, and such early entanglements can hinder young people's ability to accumulate wealth. In order to aid younger consumers, it is critical for researchers to explore how financially knowledgeable young adults are. Understanding the factors that contribute to or detract from the acquisition of financial knowledge can help policymakers design effective interventions targeted at the young population.

In order to examine how well equipped young people are to make financial decisions, we analyzed financial literacy questions newly added to the National Longitudinal Survey of Youth fielded in 2007-2008. We used this rich dataset to study the relationship between financial literacy and respondents' sociodemographic characteristics, family characteristics, and peer characteristics. Our aim was to examine three key research questions: 1) How well equipped are young people to make financial decisions? 2) What are the determinants of financial literacy among young people? 3) How can this information aid policymakers seeking to devise interventions aimed at young consumers?

We found that most young adults are not well equipped to make financial decisions: only $27 \%$ of young people in our sample possessed knowledge of basic financial concepts including inflation and risk diversification and could do simple interest rate calculations. Financial illiteracy is not only widespread but is particularly acute among specific groups, such as women, Blacks, Hispanics, and those with low educational attainment. Additionally, we linked financial 
literacy to cognitive ability, time preferences, teachers' interest in students, parental background, and peer characteristics.

We found that both educational attainment and cognitive ability are important determinants of financial literacy, but they are not the sole determinants. In fact, many variables continued to be important predictors of financial literacy, even after accounting for education and cognitive ability. Moreover, education and cognitive ability alone fail to account for the wide variation in financial knowledge among the young. For this reason, researchers and policymakers alike would benefit from gathering information on financial literacy; often-used indicators thought to proxy for financial literacy, such as education, do a poor job of measuring respondents' financial knowledge. We also found that financial knowledge among the young is strongly influenced by family background. Respondents whose mothers had a college education were more likely to understand inflation. Moreover, young respondents whose parents had stocks or retirement savings when they were teenagers were more likely to know about risk diversification. Thus, financial knowledge can be passed on from parents to children. According to our estimates, a college-educated male whose parents had stocks and retirement savings is about 50 percentage points more likely to know about risk diversification than a female with less than a high school education whose parents were not wealthy (did not own stocks or retirement savings).

These results should be of interest to policymakers concerned with financial well-being and the balance between personal and institutional responsibility. First, financial knowledge should not be taken for granted, even among the young. Second, financial illiteracy is particularly severe among specific groups such as minorities and women. Young women are now more likely to have a college degree than men and participate actively in the labor market, yet 
their level of financial literacy remains very low. Targeting financial education programs to the groups that need them most could increase their effectiveness. Third, given the influence of parents in shaping financial literacy, initiatives such as financial literacy courses in school may be particularly helpful for those who do not have college-educated parents or whose parents do not have experience investing in stocks and other complex assets. Information on factors that influence the accumulation of financial knowledge reported in this paper can aid policymakers trying to help younger consumers navigate today's increasingly complex financial marketplace.

\section{LITERATURE REVIEW}

The financial situation of today's young people is characterized increasingly by high levels of debt. Between 1997 and 2007, average undergraduate student loan debt rose from $\$ 9,250$ to $\$ 19,200$ - a $58 \%$ increase after accounting for inflation. Average debt for college students graduating with loans rose six percent in just one year between 2006 and 2007, from $\$ 18,976$ to $\$ 20,098$ (Reed 2008). Additionally, median credit card debt among college students grew from \$946 in 2004 to \$1,645 in 2009 (both figures in 2004 dollars), a 74\% increase (Sallie Mae 2009).

Recent survey results also suggest that these debt loads are causing anxiety among young people and influencing major labor decisions: a 2006 USA Today/National Endowment for Financial Education (NEFE) poll of young adults ages 22 to 29 found that, of those with debt, $30 \%$ said they worried about it frequently; $29 \%$ had put off or decided against furthering their education because of debt; and $22 \%$ had taken a job they would not have taken otherwise because of debt. There are other potentially costly consequences of accumulating high levels of debt early on, such as bankruptcy (Roberts and Jones 2001). For instance, the U.S. Senate Committee on Banking, Housing and Urban Affairs reported in 2002 that the fastest-growing 
group of bankruptcy filers was those age 25 and younger. These high levels of debt may also prevent young workers from taking advantage of employer-provided pensions, tax-favored assets, or building up a buffer to insure against shocks: $55 \%$ of young adults report they are not saving in either an individual retirement account (IRA) or a $401(\mathrm{k})$ account, and $40 \%$ do not have a savings account that they contribute to regularly (USA Today/NEFE 2006).

These debt loads are of particular concern given recent evidence that young people may lack sufficient knowledge to successfully navigate their financial decisions: for instance, a National Council on Economic Education study of high school students and working-age adults showed widespread lack of knowledge among respondents regarding fundamental economic concepts (NCEE 2005), confirming evidence provided by the Jump\$tart Coalition for Personal Financial Literacy (Mandell 2004). Policymakers have become so concerned about young people's finances that the Credit Card Accountability, Responsibility, and Disclosure (CARD) Act of 2009 included several provisions specifically targeted at protecting younger credit card consumers. For instance, credit cards will no longer be issued to young people under the age of 21 unless they have an adult co-signer or can show proof that they have the means to repay the debt; college students will be required to receive permission from parents or guardians in order to increase credit limits on joint accounts; and those under 21 will be protected from prescreened credit card offers unless they specifically opt in for the offers.

Previous research has found that financial literacy can have important implications for financial behavior: people with low financial literacy are more likely to have problems with debt (Lusardi and Tufano 2009), less likely to participate in the stock market (van Rooij, Lusardi, and Alessie 2007), less likely to choose mutual funds with lower fees (Hastings and Tejeda-Ashton 2008), less likely to accumulate wealth and manage wealth effectively (Stango and Zinman 
2007; Hilgert, Hogarth, and Beverly 2003), and less likely to plan for retirement (Lusardi and Mitchell 2006, 2007a, 2009). Financial literacy is an important component of sound financial decision-making, and many young people wish they had more financial knowledge: $84 \%$ of college students said they needed more education on financial management topics, $64 \%$ would have liked to receive information about financial management topics in high school, and $40 \%$ would have liked to receive such information as college freshmen (Sallie Mae 2009). Understanding financial literacy among young people is thus of critical importance for policymakers in several arenas: it can aid those who wish to devise effective financial education programs targeted at young people, and it can also aid those who wish to devise legislation to protect younger consumers.

Our study contributes to the literature in three important ways. First, we analyzed levels of financial literacy among the young using a new nationally representative dataset: the latest wave of the NLSY97. Second, we used this dataset to examine how levels of financial literacy differed across a wide range of sociodemographic characteristics, family characteristics, and peer characteristics. Third, we used multivariate analysis to identify several key determinants of financial literacy among young people. In what follows, we describe our study of financial literacy in a nationally representative sample of young people.

\section{DATASET}

The NLSY97 is a nationally representative sample of the U.S. youth population aged $12-$ 17 in 1997. The survey was designed to document young adults' transition from school to work and to identify defining characteristics of that transition. Consequently, the survey reports extensive information on respondent labor market behavior, educational experience, and family and community characteristics. In addition to the youth interview, the NLSY97 includes a 
separate interview with each youth's parent, designed to provide detailed parental characteristics as well as information about the home environment. We were able to include a small set of financial literacy questions in Wave 11 of the survey, fielded in 2007-2008 when respondents were 23-28 years old. To construct the final sample, we deleted observations with missing data for some of the variables included in our analysis (specifically on smoking, teachers' interest in students, and peer characteristics). Our final sample included 7,138 respondents. As sample weights for Wave 11 are currently unavailable, the statistics and findings below refer only to data using the weights in the original 1997 sample. In what follows, we used both the nationally representative sample of youths as well as the Black and Hispanic oversample. Summary statistics for the variables employed are reported in Appendix Table 1.

\section{METHODOLOGY}

The three financial literacy questions included in wave 11 of the NLSY were the questions that Lusardi and Mitchell $(2006,2008)$ originally designed for the 2004 HRS and that have been added to many surveys in the United States and abroad. The wording of the questions was as follows:

- Suppose you had $\$ 100$ in a savings account and the interest rate was $2 \%$ per year. After 5 years, how much do you think you would have in the account if you left the money to grow: more than $\$ 102$, exactly $\$ 102$, or less than $\$ 102$ ? \{Do not know; refuse to answer?

- Imagine that the interest rate on your savings account was $1 \%$ per year and inflation was $2 \%$ per year. After 1 year, would you be able to buy more than, exactly the same as, or less than today with the money in this account? \{Do not know; refuse to answer? 
- Do you think that the following statement is true or false? "Buying a single company stock usually provides a safer return than a stock mutual fund." \{Do not know; refuse to answer?

These questions tested the knowledge of basic but fundamental financial concepts. The first two questions, which we refer to as the "interest rate" and "inflation" questions, tested whether respondents were knowledgeable about inflation and possessed basic financial numeracy. The third question, on "risk diversification," evaluated respondents' knowledge of risk diversification, a crucial element of an informed investment decision. These questions have been shown to differentiate well between naïve and sophisticated respondents (Lusardi and Mitchell 2006, 2008). In what follows, we first report univariate analyses of the responses to the three financial literacy questions across a wide range of characteristics. This allowed us to assess which factors were associated with financial literacy. Subsequently, we performed a multivariate analysis to determine which variables continued to have an impact on financial literacy later in life, even when accounting for a wide range of characteristics.

These survey data are unique in that they permitted us to link financial literacy later in life to characteristics measured when respondents were teenagers. Several considerations guided our selection of the variables for the empirical analysis. First, we were interested in variables that could proxy for preferences, such as impatience, which might influence whether young people invest in financial knowledge. Second, we considered variables related to costs and opportunities for learning, such as cognitive ability, schooling, and exposure to financial knowledge via family and peers.

Researchers have hypothesized that financial knowledge may be related to a person's time preferences: that is, those who discount the future more heavily may be less willing to 
invest resources in acquiring financial knowledge, since such an investment has a delayed payoff. For instance, a recent study found that it is disproportionately those who are patient who self-select into financial education programs (Meier and Sprenger 2007). As a proxy for time preference in this study, we used an indicator of whether a respondent had ever smoked. Prior research has reported that impatience is associated with higher rates of smoking (Fuchs 1982), and current smokers discount the value of delayed hypothetical monetary outcomes more than a comparison group (Bickel, Odum, and Madden 1999). Benjamin, Brown, and Shapiro (2006) also used smoking as a proxy for time preferences in their examination of NLSY79 data. We also considered other demographic characteristics, such as gender and race/ethnicity, to account for the many differences among the young.

One advantage of the NLSY is that it administered the Armed Services Vocational Aptitude Battery (ASVAB), which is commonly used as an indicator of cognitive ability. The ASVAB consists of several subtests that measure vocational aptitude in twelve areas. ${ }^{1}$ The ASVAB variable that we examined was an aggregated percentile score based on four subtests: mathematical knowledge, arithmetic reasoning, word knowledge, and paragraph comprehension. This variable was similar to the Armed Forces Qualifying Test (AFQT) score in the NLSY79 dataset that other researchers have used as a proxy for cognitive ability (see Benjamin, Brown, and Shapiro 2006; Cole and Shastry 2009). During Round 1 of the NLSY97, 79.3\% of respondents completed the computer-adaptive form of the ASVAB (we accounted for those lacking a score in our empirical work). ${ }^{2}$

In addition to cognitive ability, we also included respondent educational attainment, gathered from Wave $11 .^{3}$ We were also interested in examining whether financial knowledge in 
young adulthood might be related to teachers during the grade school years. Accordingly, we measured this by respondent reports as to whether their teachers were interested in the students.

In addition to individual characteristics, we added family background variables to the regressions. Much prior work has argued that individuals learn via interaction with others, in particular, family and friends. For instance, Mandell (2008) reported that financially literate high school students were disproportionately those whose parents had college degrees. Our analysis therefore included the mother's educational attainment. ${ }^{4}$ Sharing among family members can also play an important role in household financial decisions; for instance, $\mathrm{Li}$ (2009) found that people's likelihood of entering the stock market within five years was 30 percent higher if their parents or children had entered the market in the prior five years. Interestingly, the finding that children are more likely to invest in stocks if the family of origin invested in stocks holds true even among minorities (Chiteji and Stafford 1999). Because we were interested in the influences of family financial circumstances, we also examined whether the respondent's parent owned a home, had retirement savings (pensions or retirement plans, tax-deferred plans such as thrift/savings, 401(k)s, profit sharing or stock ownership plans, and IRAs or Keogh plans), was banked or unbanked (had checking accounts, saving accounts, or money market mutual funds), and owned stocks or mutual funds. ${ }^{5}$ The first two variables were indicators of family wealth, while the latter two variables proxied for financial sophistication. In light of research by Hong, Kubik, and Stein (2004) showing that churchgoers are more likely to invest in stocks, we also looked at whether the respondent's parents attended church regularly, as a proxy for social interactions with non-family members. Our analysis improved upon previous work as it allowed us to assess whether the interaction with others influences financial knowledge, which can in turn affect financial behavior. 
To pursue this issue further, we considered the influence not just of family or other adults, but also of peers. In several studies of saving and financial decision-making, peers were found to be one of the key contributors of information and financial advice (Hong, Kubik, and Stein 2004; Brown et al. 2008). For example, when asked how they make financial decisions, a high fraction of respondents reported consulting friends and colleagues (Lusardi and Mitchell 2006; van Rooij, Lusardi, and Alessie 2007). Peers were also important in decisions concerning pension participation and contribution (Duflo and Saez 2003, 2004). This led us to investigate the question of whether peer influences — even those that happen early in life — could be linked to levels of financial knowledge later in life.

We also included several peer characteristics: percentage of peers going to college (as a proxy for peer educational attainment), percentage of peers attending church (as a proxy for peer social involvement), and percentage of peers who smoked (as a proxy for peer time preferences). These percentages were reported by the respondent. Note that the peers in this study were not "current peers," but rather peers from the respondent's teenage years. Our results therefore examined the long-term effects of high school peer influences on subsequent financial literacy (as opposed to the influences of current peers).

\section{DESCRIPTIVE FINDINGS}

Panel A of Table 1 reports results from the three questions that measured respondent levels of financial literacy. While nearly $80 \%$ of respondents answered the interest rate question correctly, only $54 \%$ answered the inflation question correctly, and $15 \%$ responded that they did not know the answer to the inflation question. Only $47 \%$ answered the risk diversification question correctly, and 38\% responded that they did not know the answer. The large "don't know" response rate was particularly troubling, as previous research has found that "don't know" 
answers identified respondents with very low levels of financial knowledge (Lusardi and Mitchell 2006, 2007a; Lusardi and Tufano 2009; van Rooij, Lusardi, and Alessie 2007). In any case, the low correct response rates, particularly to the inflation and risk diversification questions, indicated that many young people lack knowledge of basic financial concepts.

[Insert Table 1 about here]

Panel B of Table 1 shows that the correct answers to these three financial literacy questions were highly positively correlated: those able to answer one of the financial literacy questions correctly were also more likely to answer the other questions correctly. However, only $27 \%$ of respondents answered all three questions correctly, and only about $46 \%$ got the first two questions right. Thus, our findings show that lack of financial knowledge is widespread among the young.

\section{Who Is Financially Illiterate?}

While the overall level of financial knowledge was low among the young, there were significant differences according to sociodemographic, family, and peer characteristics. Table 2 tabulates the proportions of correct answers to the three financial literacy questions according to these characteristics. We highlight some of the more salient results below.

[Insert Table 2 about here]

\section{Sociodemographic Characteristics}

We found that there were large differences in financial literacy between women and men. Women were less likely to respond correctly to each of the three questions, and there was a nearly $13 \%$ gap for correct response rates to the inflation and risk diversification questions. These differences between women and men were statistically significant. Lusardi and Mitchell (2008) found similar sex differences among older HRS respondents. This finding is corroborated 
by Lusardi and Tufano (2009), who explored debt literacy for a representative U.S. sample; in studies of narrower samples (Agnew and Szykman 2005; Lusardi, Keller, and Keller 2008); and in studies of other countries (van Rooij, Lusardi, and Alessie 2007; Lusardi and Mitchell 2007b; Smith and Stewart 2008). Consequently, there is now fairly robust evidence confirming that women do not do well in financial calculations and do not have a firm grasp of inflation and risk diversification.

Table 2 also reveals differences in financial literacy according to race and ethnicity: whites were more likely than Black and Hispanic respondents to answer all three financial literacy questions correctly. The gap in the correct response rate between Black respondents and white respondents was about $17 \%$ for the inflation question and nearly $12 \%$ for the risk diversification question. The corresponding gaps for Hispanic respondents were about $12 \%$ and $7 \%$. These differences were statistically significant. This finding was consistent with other studies that have found differences in financial literacy according to racial and ethnic differences among high school students (Mandell 2008) and other age groups (Lusardi and Mitchell 2007a; Lusardi and Tufano 2009).

Table 2 also reveals a strong association between financial literacy and cognitive ability. Correct response rates increased substantially for higher levels of cognitive ability. The difference between the third quartile (ASVAB: 50-75) and the fourth quartile (ASVAB: $75+$ ) was particularly notable: the correct response rate for the inflation and risk diversification questions was about 21 percentage points higher for those who were in the fourth quartile instead of the third, and the differences were statistically significant. Our finding that cognitive ability was strongly linked to financial literacy corroborates preliminary findings from another survey of financial literacy among young people. ${ }^{6}$ There were also large differences in financial literacy 
according to educational attainment, especially for those who attended college - their correct response rates were over 20 percentage points higher than for those who graduated from high school for the inflation and risk diversification questions, and the differences were statistically significant.

\section{Family Characteristics}

Mother's education was strongly associated with financial literacy, especially if a respondent's mother graduated from college: those whose mothers graduated from college had correct response rates that were about 19 percentage points higher for the inflation question and 18 percentage points higher for the risk diversification question with respect to those whose mothers graduated from high school, and the differences were statistically significant. Each of our proxies for family wealth and family financial sophistication was also associated with financial literacy: for instance, the difference in correct response rates to the inflation and risk diversification questions was at least 11 percentage points for each of these variables, and these differences were statistically significant. Whether it was wealth, financial sophistication, or both that mattered for respondents' financial literacy was analyzed in more detail in the next section, where we considered all of these variables together. Nevertheless, this simple univariate analysis revealed the importance of considering family characteristics when analyzing financial literacy among young people.

\section{Peer Characteristics}

Table 2 also revealed associations between peer characteristics and financial literacy. Those with a high percentage of peers who planned to attend college did about 7 percentage points better on the inflation and risk diversification questions; those with a higher percentage of peers who attended church did better on all three questions; and those with a low percentage of 
peers who smoked also did substantially better on each of the three questions, with correct response rates about 9 percentage points higher for the inflation and risk diversification questions. All of these differences were statistically significant (except with whether peers attended church for the interest rate question). Thus, peer characteristics may also play a role in explaining differences in financial literacy.

\section{MULTIVARIATE ANALYSIS}

In this section, we performed a multivariate analysis that permitted us to assess which factors were still linked to financial literacy, even when controlling for many other characteristics. We used three different specifications in the analysis: in specification I, we considered only sociodemographic characteristics; in specification II, we considered sociodemographic characteristics as well as family characteristics; and in specification III, we considered sociodemographic characteristics, family characteristics, and peer characteristics. ${ }^{7}$

Our underlying model was as follows:

$$
y^{*}=\mathbf{x} \boldsymbol{\beta}+\varepsilon, \quad y= \begin{cases}1 & \text { if } y^{*}>0 \\ 0 & \text { else }\end{cases}
$$

where $y^{*}$ is an unobservable characteristic: a respondent's propensity to answer a financial literacy question correctly, and $y$ is a binary outcome variable indicating that a respondent gave the correct response if his propensity to respond correctly was above zero. The vector $\mathbf{x}$ contains respondent characteristics that depend on the specification, $\boldsymbol{\beta}$ is a vector of parameters to be estimated, $\varepsilon$ is a continuously distributed variable independent of $\mathbf{x}$, and the distribution of $\varepsilon$ is symmetric about zero.

We used a probit model for our analysis so that this gave rise to a binary response model of the form:

$$
\mathrm{P}(y=1 \mid \mathbf{x})=\Phi(\mathbf{x} \boldsymbol{\beta})
$$


where $\Phi$ is a cumulative distribution function (cdf). Our primary goal was to explain the effects of the respondent characteristics $x_{j}$ on the probability of responding correctly to a financial literacy question. In our model, if $x_{K}$ is a binary explanatory variable, then the marginal effect from changing $x_{K}$ fom zero to one, holding all other variables fixed, is simply

$$
\Phi\left(\beta_{1}+\beta_{2} x_{2}+\ldots+\beta_{K-1} x_{K-1}+\beta_{K}\right)-\Phi\left(\beta_{1}+\beta_{2} x_{2}+\ldots+\beta_{K-1} x_{K-1}\right) .
$$

Note that this expression depends on all other values of the other $x_{j}$. We calculated the marginal effects by setting all of the other independent variables to their mean values. Our model therefore allowed us to interpret the marginal effect from changing a discrete explanatory variable $x_{K}$ fom zero to one as the change in the probability of responding correctly to the financial literacy question. If $x_{j}$ is continuous, as is the case for the ASVAB variable, then $\frac{\partial P(y=1 \mid \mathbf{x})}{\partial x_{j}}=g(\mathbf{x} \boldsymbol{\beta}) \beta_{j}, \quad$ where $g(z) \equiv \frac{d \Phi}{d z}(z)$.

However, $\Phi$ is a strictly increasing cdf, so that $g(z)>0$ for all $z$. Therefore, the sign of the marginal effect of a change in $x_{j}$ is given by the sign of $\beta_{j}$. Our model closely followed the probit model specified by Woolridge (2002). The marginal effects that we calculated are reported in Table 3.

[Insert Table 3 about here]

Several important findings emerged from our estimates. Even after accounting for many sociodemographic, family, and peer characteristics, women were still substantially less financially literate than their male counterparts. Women were about 6 percentage points less likely to answer the interest rate question correctly, 15 percentage points less likely to answer the inflation question correctly, and nearly 16 percentage points less likely to answer the risk 
diversification question correctly. This result shows that sex is a strong predictor of financial literacy, even after accounting for many characteristics.

Financial literacy was also strongly associated with cognitive ability, and this relationship was highly non-linear; financial literacy, as measured by each of the three questions, was a convex function of the ASVAB score, which indicates that returns for financial literacy increased sharply with increasing cognitive ability. These results showed that cognitive ability, even when measured during a respondent's teenage years, was a strong determinant of financial literacy.

Teachers' interest in students (as reported by the respondents) had a small but significant positive effect on a respondent's probability of answering the inflation question correctly, even after controlling for cognitive ability and educational attainment. This suggests that the quality and motivation of teachers influence financial literacy among young people, consistent with the findings of Lusardi and Mitchell (2009) that those living in states that mandated financial literacy and spent more on education per pupil were more likely to display higher financial knowledge later in life.

There was a strong positive relationship between educational attainment (measured in wave 11 of the NLSY97) and financial literacy, in particular for those who had attended some college: they were 6 percentage points more likely to answer the interest rate question correctly, 17 percentage points more likely to answer the inflation question correctly, and 18 percentage points more likely to answer the risk diversification question correctly. Even having graduated from high school made respondents more financially literate; for example, those who graduated from high school were 7 percentage points more likely to answer the inflation question correctly. Educational attainment was clearly a strong determinant of financial literacy. 
Family characteristics were also found to be important determinants of financial literacy. In particular, parents' education was a strong predictor of financial literacy: those whose mothers graduated from college were nearly 5 percentage points more likely to answer the inflation question correctly. Family financial sophistication also played an important role: those whose parents owned stocks were over 7 percentage points more likely to answer the risk diversification question correctly, and those whose parents had retirement savings were 6 percentage points more likely to answer this question correctly. Since retirement savings referred to $401(\mathrm{k}) \mathrm{s}$, profit sharing or stock ownership plans, IRA or Keogh plans, where individuals have to decide how to allocate retirement wealth, this variable is likely to proxy for knowledge and experience in dealing with stocks. Stocks and retirement savings were most likely not mere proxies for wealth; we controlled for wealth in our specifications by including dummies for whether the parents owned a home or had a checking account, two of the most common components of wealth (Lusardi, Cossa, and Krupka 2001). The result that children whose parents owned stocks (either in private wealth or retirement wealth) were more likely to understand risk diversification suggests that some financial knowledge may be passed on directly from parents to their children, as other papers have found (Chiteji and Stafford 1999; Li 2009).

Finally, although peer characteristics were not strongly associated with financial literacy after controlling for so many other variables, there was still a negative relationship between having a high percentage of peers who smoked and answering the inflation question correctly. This suggests that characteristics of peers when respondents were teenagers can influence respondents' levels of financial literacy later in life.

Admittedly, the ten-year gap between the measurement of the dependent and independent variables places some limitations on the interpretation of our results. For instance, it is difficult at 
times to assign a causal interpretation to our estimated coefficients. And one might note that the low pseudo R-squared values in our regressions indicated that our explanatory variables left much variation unaccounted for, a fact that is unsurprising given the many factors that could influence the accumulation of financial knowledge, especially over the course of ten years. Nonetheless, it is remarkable that many of the characteristics we examined, even when measured at a young age, still determined, to some extent, an individual's level of financial knowledge later in life.

\section{WHAT HAVE WE LEARNED?}

As the complexity of financial decisions increases and individuals are put in charge of making these decisions even at a young age, it is important to find ways to equip people with adequate financial knowledge. Previous studies have shown that broad groups of the population are not financially literate; these people may be particularly unlikely and unable to manage their finances effectively, and to plan adequately for the future. This paper added to the existing knowledge by exploring what younger adults know and do not know as determined by a set of simple questions that assessed their financial literacy. We found that financial literacy was severely lacking among young adults; only $27 \%$ of young adults know about inflation and risk diversification and can do simple interest rate calculations. Moreover, women proved to be the least financially literate. Sex differences between women and men persisted even after accounting for many demographic characteristics, family background characteristics, and peer characteristics. Prior work showed that women tended to display low financial literacy later in life (Lusardi and Mitchell 2006, 2008). Thus, lack of financial literacy seems to persist for long periods and sometimes throughout the lifetime. Given the strong link between financial literacy and financial management and retirement planning found in other studies (Lusardi and Mitchell 
2007a, 2008; Hilgert, Hogarth, and Beverly 2003), it may be important to find ways to foster financial knowledge in the population as a whole and among the groups who are more disadvantaged. Similarly, it may be important to develop programs targeted specifically to women, since they display not only much lower financial knowledge but also large differences in investment and saving behavior (Hira and Loibl 2008; Lusardi, Keller, and Keller 2008).

Our study also found an important channel through which young adults acquire financial knowledge: parents. In both the univariate and multivariate analyses, those whose mothers had high education or whose families had stocks or retirement savings were more financially literate, specifically on questions related to advanced financial knowledge, such as the workings of risk diversification. These findings confirmed the results of work analyzing financial knowledge among high school students. The small fraction of students ( 7 percent) who were deemed financially literate in the Jump\$tart Coalition for Personal Financial Literacy survey in 2006 were disproportionately white males whose parents had college degrees (Mandell 2008). It also confirmed findings of previous work among college students, where again parents were found to play a role in students' financial socialization (Cude et al. 2006).

Lack of financial knowledge may also be traced back to impatience or discounting the future heavily. In our study, we used smoking as a proxy for high rate of time preference. We found that those respondents who smoked when they were teenagers or whose peers smoked were less likely to be financially literate. Thus, in order to be effective, financial education programs have to take into account the many differences that exist among individuals, not just in terms of economic circumstances but also in terms of preferences. We also found that cognitive ability was a strong predictor of financial literacy; those with higher cognitive ability, as measured by ASVAB scores in high school, were more likely to display higher financial 
knowledge as young adults. However, many other variables remained statistically significant after accounting for cognitive ability; thus, cognitive ability was not the sole determinant of financial knowledge. In other words, there was a lot of heterogeneity in financial literacy, even when examining a narrow age group in the population.

Implications for Researchers and Consumers

Overall, the findings from this study have important implications for research related to financial literacy and household financial security. As the government and employers continue to shift the responsibility for saving and investing onto workers, it is becoming more and more important to equip workers with some basic tools to make financial decisions. While young workers face or will soon face decisions about mortgages, college funds, and retirement savings, their financial knowledge seems dangerously low and potentially inadequate to deal with the complexity of current financial markets and products. It is also important to recognize that the population of young adults displays very large differences in financial knowledge. Thus, young adults should not be considered one homogeneous group of consumers. Rather, the differences by race, sex, educational attainment, and other observable characteristics should be taken into account both in research and when considering public policy initiatives geared toward improving financial literacy.

Given the low levels of financial knowledge documented in this work, simplification of financial decisions could be very beneficial to young people. For example, this study supports the findings of Choi, Laibson, and Madrian (2006) that simplifying the way in which workers enroll into pension plans can foster pension participation, particularly among disadvantaged groups, such as Blacks and low-income workers. It also supports the findings of Lusardi, Keller, and Keller (2008) that providing a planning aid to new employees can more than double 
participation in supplementary retirement accounts. New employees at the not-for-profit institution considered in that study were disproportionately young women who had very low levels of financial literacy.

\section{Implications for Financial Education Programs}

The findings from this study also have implications for financial education programs. There were several findings in this paper supporting financial education in high school. First, if financial knowledge is acquired from parents or via interaction with others, there are groups who will not be able to benefit from these sources because their parents or friends do not have college degrees or are not financially knowledgeable. In this respect, providing financial education in high school may be particularly beneficial to children from disadvantaged backgrounds. According to our estimates, respondents whose parents did not have a college degree and lacked financial sophistication (did not have stocks or retirement savings) are approximately 15 percentage points less likely to know about risk diversification, an essential concept for making saving and investment decisions.

Second, financial literacy is not entirely determined by cognitive ability. While this variable plays a role in explaining the differences in financial knowledge among the young, it is not the only relevant factor. Thus there is a role for education in improving financial knowledge. Third and most important, it is likely to be beneficial to provide financial education before individuals engage in financial contracts and before they start making financial decisions. In this respect, it may be important to find ways to improve the effectiveness of financial literacy programs currently offered in high school.

This study also illuminated the importance of parental influences on young people's acquisition of financial knowledge. Involving parents in a financial education program could be 
more effective than only involving young people. First, parents who are engaged in such a program may take a more active role in guiding their children's financial behaviors. Second, such a program could aid those parents who lack sufficient financial knowledge to provide their children with sound financial advice.

Given the low level of financial knowledge displayed by young adults who are already out of school, it may also be important to pursue other financial education initiatives. Several firms, particularly those offering defined contribution pensions, have offered financial education programs (Bernheim and Garrett 2003; Lusardi 2004). The findings from this study show that young workers are particularly in need of these programs. Other studies also show that the young are those more susceptible to making financial mistakes (Agarwal et al. 2007). Given the substantial differences that exist among the young, "one-size-fits-all" programs are unlikely to be effective. The results suggest that there may be substantial gains in financial literacy when programs are targeted to women, minorities, such as Blacks and Hispanics, and those with low educational attainment.

We would also like to highlight, as already argued in Lyons and Neelakantan (2008), that it may be particularly difficult to evaluate the effectiveness of financial education among the young. For example, according to the life-cycle model of saving, young individuals facing an upward-sloping age-earnings profile should borrow rather than save to smooth consumption over the life-cycle. However, many financial education programs simply assess whether individuals increase their saving after having been exposed to financial education programs. In this respect, it is important to develop new ways to assess the impact of financial education on the young, including examining levels of debt and borrowing behavior among the young. ${ }^{8}$ 


\section{ENDNOTES}

1. The areas were arithmetic reasoning, assembling objects, auto information, coding speed, electronics information, general science, mathematics knowledge, mechanical comprehension, numerical operations, paragraph comprehension, shop information, and word knowledge.

2. We did not have ASVAB responses for 1,128 of respondents so we included a missing variable dummy for this group in all regressions.

3. Note that this was the only control variable measured during Wave 11; the remainder were measured in Wave 1.

4. Similar results were obtained when we considered data about the father. Nevertheless, because there were many missing observations for father's education, we relied instead on mother's education for which the missing data problem was far less pervasive.

5. Parental information was missing for approximately $10 \%$ of the sample. Statistics reported in the tables refer to the sample for which parents' wealth was available. We added a dummy for missing data about parents' wealth in our regressions. For a detailed analysis of the wealth data in the NLSY97, see Lusardi, Cossa, and Krupka (2001).

6. We thank Lewis Mandell for sharing with us preliminary results from the 2008 wave of the Jump\$tart Coalition for Personal Financial Literacy, where he linked financial literacy with the score on the ACT or SAT exam. His preliminary findings indicated that these scores were very powerful predictors of differences in financial literacy among high school seniors.

7. Because data were missing for family characteristics and respondent's educational level, we included dummies for missing observations in all of our regressions. For brevity, these estimates are not reported in the tables, but are available upon request. 
8. See also the discussion of financial education programs and their evaluation in Lyons et al. (2006). 


\section{REFERENCES}

Agarwal, Sumit, John C. Driscoll, Xavier Gabaix, and David Laibson. 2007. The Age of Reason: Financial Decisions over the Lifecycle. NBER Working Paper n. 13191.

Agnew, Julie, and Lisa Szykman. 2005. Asset Allocation and Information Overload: The Influence of Information Display, Asset Choice and Investor Experience. Journal of Behavioral Finance, 6: 57-70.

Benjamin, Daniel J., Sebastian A. Brown, and Jesse M. Shapiro. 2006. Who Is "Behavioral”? Cognitive Ability and Anomalous Preferences. Mimeo, University of Chicago.

Bernheim, Douglas, and Daniel Garrett. 2003. The Effects of Financial Education in the Workplace: Evidence from a Survey of Households. Journal of Public Economics, 87: 1487-1519.

Bickel, Warren K., Amy L. Odum, and Gregory J. Madden. 1999. Impulsivity and Cigarette Smoking: Delay Discounting in Current, Never, and Ex-Smokers. Psychopharmacology, $146(4): 447-454$.

Brown, Jeffrey, Zoran Ivkovich, Paul Smith, and Scott Weisbenner. 2008. Neighbors Matter: Causal Community Effects and Stock Market Participation. Journal of Finance, 63 (3): 1509-1531.

Chiteji, Ngina and Frank Stafford. 1999. Portfolio Choices of Parents and Their Children as Young Adults: Asset Accumulation by African American Families. American Economic Review Papers and Proceedings, 89: 377-380

Choi, James, David Laibson, and Brigitte Madrian. 2006. Reducing the Complexity Costs of 401(k) Participation Through Quick Enrollment (TM). NBER Working Paper n. 11979.

Cole, Shawn, and Gauri Kartini Shastry. 2009. Smart Money: The Effect of Education, Cognitive Ability, and Financial Literacy on Financial Market Participation. Harvard Business School Working Paper n. 09-071.

Cude, Brenda, Frances Lawrence, Angela Lyons, Kaci Metzger, Emily LeJeune, Loren Marks, and Krisanna Machtmes. 2006. College Students and Financial Literacy: What They Know and What We Need to Learn. Proceedings of the Eastern Family Economics and Resource Management Association, 102-109.

Duflo, Esther, and Emmanuel Saez. 2003. The Role of Information and Social Interactions in Retirement Plan Decisions: Evidence from a Randomized Experiment. Quarterly Journal of Economics, 118: 815-842.

Duflo, Esther, and Emmanuel Saez. 2004. Implications of Pension Plan Features, Information, and Social Interactions for Retirement Saving Decisions. In Pension Design and Structure: New Lessons from Behavioral Finance, edited by Olivia S. Mitchell and Stephen Utkus (137-153). Oxford: Oxford University Press. 
Fuchs, Victor R. 1982. Time Preference and Health: An Exploratory Study. In Economic Aspects of Health, edited by Victor R. Fuchs (93-120). Chicago: The University of Chicago Press.

Hastings, Justine, and Lydia Tejeda-Ashton. 2008. Financial Literacy, Information, and Demand Elasticity: Survey and Experimental Evidence from Mexico. NBER Working Paper n. 14538.

Hilgert, Marianne, Jeanne Hogarth, and Sondra Beverly. 2003. Household Financial Management: The Connection Between Knowledge and Behavior. Federal Reserve Bulletin, 309-322.

Hira, Tahira, and Cazilia Loibl. 2008. Gender Differences in Investment Behavior. In Handbook of Consumer Finance Research, edited by Jing Jian Xiao (253-270). New York: Springer.

Hong, Harrison, Jeffrey Kubik, and Jeremy Stein. 2004. Social Interaction and Stock Market Participation. Journal of Finance, 59: 137-163.

Li, Geng. 2009. Information Sharing and Stock Market Participation: Evidence from Extended Families. Mimeo, Federal Reserve Board.

Lusardi, Annamaria. 2004. Savings and the Effectiveness of Financial Education. In Pension Design and Structure: New Lessons from Behavioral Finance, edited by Olivia S. Mitchell and Stephen Utkus (157-184). Oxford: Oxford University Press.

Lusardi, Annamaria, Ricardo Cossa, and Erin Krupka. 2001. Savings of Young Parents. Journal of Human Resources, 34: 762-794.

Lusardi, Annamaria, Punam Keller, and Adam Keller. 2008. New Ways to Make People Save: A Social Marketing Approach. In Overcoming the Saving Slump: How to Increase the Effectiveness of Financial Education and Saving Programs, edited by Annamaria Lusardi (209-236). Chicago: University of Chicago Press.

Lusardi, Annamaria, and Olivia S. Mitchell. 2006. Financial Literacy and Planning: Implications for Retirement Wellbeing. Working Paper, Pension Research Council, Wharton School, University of Pennsylvania.

Lusardi, Annamaria, and Olivia S. Mitchell. 2007a. Baby Boomer Retirement Security: The Role of Planning, Financial Literacy, and Housing Wealth. Journal of Monetary Economics, 54: $205-224$.

Lusardi, Annamaria, and Olivia S. Mitchell. 2007b. Financial Literacy and Retirement Preparedness: Evidence and Implications for Financial Education. Business Economics, 42 (1): $35-44$.

Lusardi, Annamaria, and Olivia S. Mitchell. 2008. Planning and Financial Literacy: How Do Women Fare? American Economic Review, 98: 413-417. 
Lusardi, Annamaria, and Olivia S. Mitchell. 2009. How Ordinary People Make Complex Economics Decisions: Financial Literacy and Retirement Readiness, mimeo, Dartmouth College.

Lusardi, Annamaria, and Peter Tufano. 2009. Debt Literacy, Financial Experiences, and Overindebtedness. NBER Working Paper n. 14808.

Lyons, Angela, Lance Palmer, Koralalage Jayaratne, and Erik Scherpf. 2006. Are We Making the Grade? A National Overview of Financial Education and Program Evaluation. The Journal of Consumer Affairs, 40 (2): 208-235.

Lyons, Angela, and Urvi Neelakantan. 2008. Potential and Pitfalls of Applying Theory to the Practice of Financial Education. The Journal of Consumer Affairs, 42 (1): 106-112.

Mandell, Lewis. 2004. Financial Literacy: Are We Improving? Results of the 2004 National Jump\$tart Survey. Washington, D.C.: Jump\$tart Coalition for Personal Financial Literacy.

Mandell, Lewis. 2008. Financial Literacy in High School. In Overcoming the Saving Slump: How to Increase the Effectiveness of Financial Education and Saving Programs, edited by Annamaria Lusardi (257-279). Chicago: University of Chicago Press.

Meier, Stephan, and Charles Sprenger. 2007. Selection into Financial Literacy Programs: Evidence from a Field Study. Federal Reserve Bank of Boston Discussion Paper n. 07-5.

National Council on Economic Education. 2005. What American Teens and Adults Know About Economics. http://207.124.141.218/WhatAmericansKnowAboutEconomics_0426053.pdf.

Reed, Matthew. 2008. Student Debt and the Class of 2007. The Project on Student Debt. http://projectonstudentdebt.org/files/pub/classof2007.pdf.

Roberts, James A., and Eli Jones. 2001. Money Attitudes, Credit Card Use, and Compulsive Buying Among American College Students. The Journal of Consumer Affairs, 35 (21): 213-240.

Sallie Mae. 2009. How Undergraduate Students Use Credit Cards. http://www.salliemae.com/NR/rdonlyres/0BD600F1-9377-46EA-AB1F6061FC763246/10744/SLMCreditCardUsageStudy41309FINAL2.pdf.

Smith, Barbara, and Fiona Stewart. 2008. Learning from the Experience of OECD Countries: Lessons for Policy, Programs, and Evaluations. In Overcoming the Saving Slump: How to Increase the Effectiveness of Financial Education and Saving Programs, edited by Annamaria Lusardi (345-367). Chicago: University of Chicago Press.

Stango, Victor, and Jonathan Zinman. 2007. Fuzzy Math and Red Ink: When the Opportunity Cost of Consumption Is Not What It Seems. Mimeo, Dartmouth College. 
USA Today/National Endowment for Financial Education. 2006. Young Adults' Finances Poll. http://www.nefe.org/Portals/0/NEFE_Files/USATodaySurvey.pdf.

van Rooij, Maarten, Annamaria Lusardi, and Rob Alessie. 2007. Financial Literacy and Stock Market Participation. NBER Working Paper n. 13565.

Woolridge, Jeffrey M. 2002. Econometric Analysis of Cross Section and Panel Data. Cambridge, MA: The MIT Press. 
TABLE 1

Patterns of Responses to Financial Literacy Questions

Panel A: Distribution of Responses to Financial Literacy Questions (\%)

\begin{tabular}{lccc}
\hline & Correct & Incorrect & Don't Know \\
\hline Interest Rate & 79.5 & 14.6 & 5.7 \\
Inflation & 54.0 & 30.7 & 15.1 \\
Risk Diversification & 46.8 & 15.8 & 37.3 \\
\hline
\end{tabular}

$N=7138$

\begin{tabular}{lccc}
\hline Panel B: Correlation Between Correct Responses & & \\
\hline & $\begin{array}{c}\text { If Correct on } \\
\text { Interest Rate } \\
\text { Question }\end{array}$ & $\begin{array}{c}\text { If Correct on } \\
\text { Inflation Question }\end{array}$ & $\begin{array}{c}\text { If Correct on Risk } \\
\text { Diversification } \\
\text { Question }\end{array}$ \\
\hline $\begin{array}{l}\text { Probability Correct on } \\
\text { Interest Rate Question }\end{array}$ & 100.0 & 84.6 & 84.5 \\
$\begin{array}{l}\text { Probability Correct on } \\
\begin{array}{l}\text { Inflation Question } \\
\text { Probability Correct on }\end{array}\end{array}$ & 57.5 & 100.0 & 66.7 \\
$\begin{array}{l}\text { Risk Diversification } \\
\text { Question }\end{array}$ & 49.7 & & \\
Column $N$ & 5,602 & 57.8 & 100.0 \\
\hline
\end{tabular}

Note: All statistics were calculated using sample weights. 
TABLE 2

Percent Correct by Sociodemographic, Family, and Peer Characteristics

\begin{tabular}{|c|c|c|c|}
\hline & Interest Rate & Inflation & Risk Diversification \\
\hline \multicolumn{4}{|l|}{ Sociodemographic Characteristics } \\
\hline Female & 76.7 & 47.8 & 40.1 \\
\hline Male & 82.2 & 60.1 & 53.3 \\
\hline White & 80.8 & 58.5 & 49.6 \\
\hline Black & 77.3 & 41.4 & 37.9 \\
\hline Hispanic & 74.6 & 46.1 & 42.3 \\
\hline ASVAB: $0-25^{*}$ & 69.9 & 33.8 & 32.9 \\
\hline ASVAB: $25-50$ & 76.9 & 46.6 & 40.5 \\
\hline ASVAB: $50-75$ & 81.4 & 58.9 & 47.3 \\
\hline ASVAB: $75+$ & 90.5 & 80.9 & 68.3 \\
\hline Teachers interested in students & 81.5 & 58.5 & 48.7 \\
\hline Teachers not interested in students & 78.8 & 52.6 & 46.2 \\
\hline Ever smoked cigarette & 77.2 & 50.8 & 43.7 \\
\hline Never smoked cigarette & 81.2 & 56.3 & 49.0 \\
\hline Educ: $<\mathrm{HS}^{*}$ & 71.1 & 33.6 & 30.5 \\
\hline Educ: HS grad & 75.6 & 44.2 & 35.7 \\
\hline Educ: $\geq$ college & 84.1 & 65.2 & 57.4 \\
\hline \multicolumn{4}{|l|}{ Family Characteristics } \\
\hline Parents attended church regularly* & 80.7 & 58.0 & 50.6 \\
\hline Parents did not attend church regularly & 79.3 & 52.4 & 44.9 \\
\hline Mother's educ: $<\mathrm{HS}^{*}$ & 74.2 & 40.6 & 36.9 \\
\hline Mother's educ: HS grad & 78.3 & 50.4 & 43.2 \\
\hline Mother's educ: some college & 80.2 & 58.0 & 48.7 \\
\hline Mother's educ: college grad + & 85.6 & 69.7 & 61.0 \\
\hline Parents owned home* & 81.6 & 58.6 & 50.8 \\
\hline Parents did not own home & 76.0 & 45.3 & 38.7 \\
\hline Parents owned stocks* & 84.8 & 66.5 & 62.7 \\
\hline Parents did not own stocks & 78.7 & 51.9 & 43.7 \\
\hline Parents had retirement savings* & 82.0 & 61.6 & 54.2 \\
\hline Parents had no retirement savings & 77.2 & 45.8 & 38.0 \\
\hline Parents unbanked* & 77.7 & 46.0 & 39.7 \\
\hline Parents banked & 81.0 & 58.7 & 50.6 \\
\hline \multicolumn{4}{|l|}{ Peer Characteristics } \\
\hline High $\%$ of peers planned to attend college & 81.2 & 57.0 & 49.9 \\
\hline Low $\%$ of peers planned to attend college & 77.3 & 50.1 & 42.7 \\
\hline High $\%$ of peers attended church regularly & 81.0 & 58.3 & 50.7 \\
\hline Low $\%$ of peers attended church regularly & 79.0 & 52.6 & 45.5 \\
\hline High $\%$ of peers smoked & 75.5 & 46.0 & 40.6 \\
\hline Low $\%$ of peers smoked & 81.0 & 57.1 & 49.1 \\
\hline
\end{tabular}

$N=7138$

Notes: All statistics were calculated using sample weights. For the characteristics denoted by an asterisk, statistics were calculated on a smaller sample due to missing data. 
TABLE 3

Multivariate Analysis of Financial Literacy: Probit Marginal Effects of Association with Correct Answers

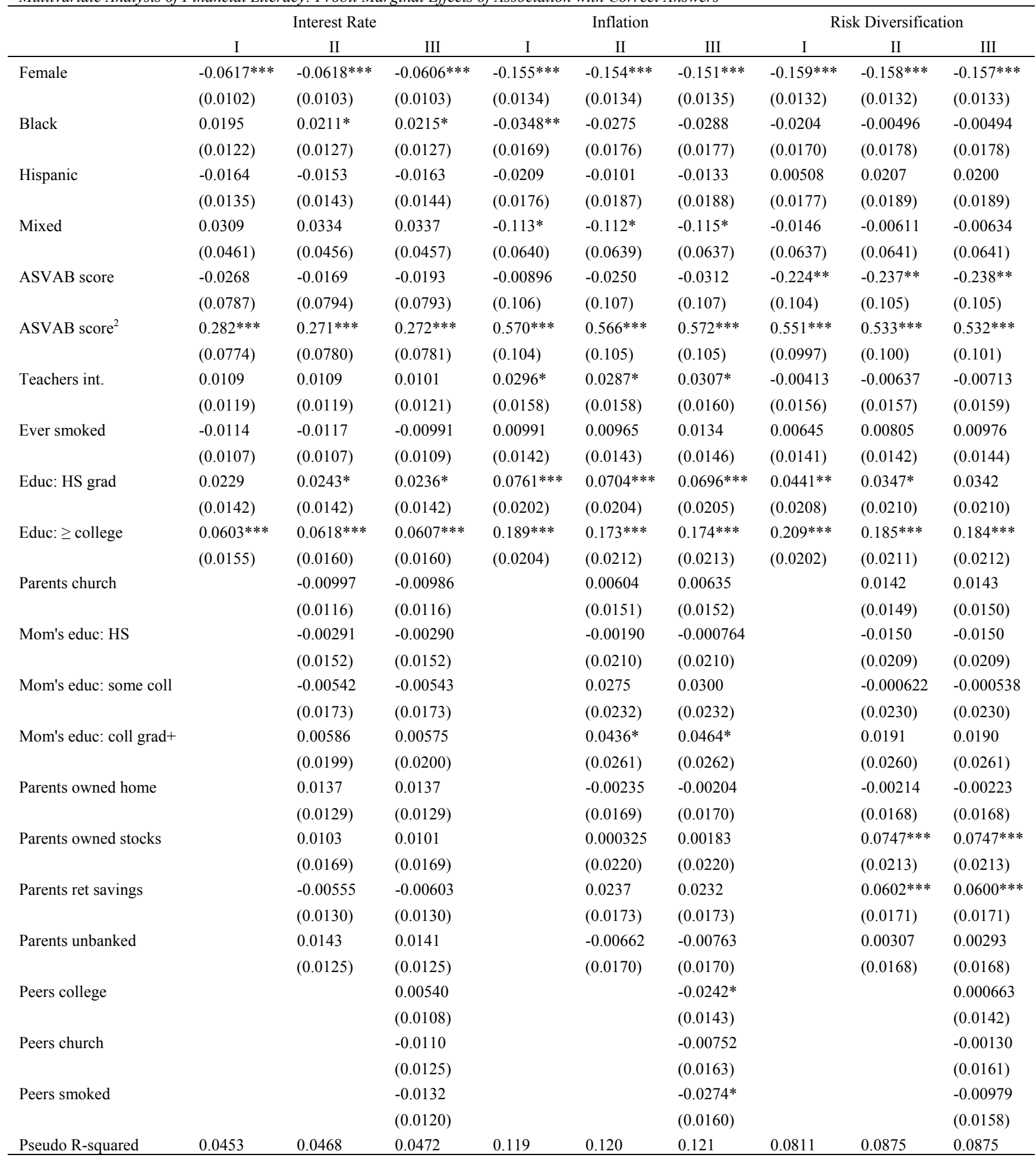

Robust standard errors in parentheses.

$N=7138$

Note: Marginal effects were calculated at the means of the independent variables.

$* p<0.1 ; * * p<0.05 ; * * * p<0.01$ 
APPENDIX TABLE 1

Statistical Summary of Variables

Mean Std. Dev.

Responses to Financial Literacy Questions

$\begin{array}{lll}\text { Interest Rate: Correct Response } & 0.80 & 0.40\end{array}$

Inflation: Correct Response $\quad 0.54 \quad 0.50$

$\begin{array}{lll}\text { Risk Diversification: Correct Response } & 0.47 & 0.50\end{array}$

Sociodemographic Characteristics

Female

$0.49 \quad 0.50$

Black

$0.16 \quad 0.37$

Hispanic

$0.13 \quad 0.33$

Mixed

$0.01 \quad 0.11$

ASVAB score

$0.50 \quad 0.27$

ASVAB score ${ }^{2}$

$0.32 \quad 0.28$

Teachers interested in students

$0.25 \quad 0.43$

Ever smoked a cigarette

$0.42 \quad 0.49$

Educ: HS grad

$0.29 \quad 0.45$

Educ: $\geq$ college

$0.55 \quad 0.50$

Family Characteristics

$\begin{array}{lll}\text { Parents attended church regularly } & 0.33 & 0.47\end{array}$

$\begin{array}{lll}\text { Mother's Educ: HS } & 0.32 & 0.47\end{array}$

Mother's Educ: Some College $\quad 0.23 \quad 0.42$

Mother's Educ: College grad $+\quad 0.20 \quad 0.40$

$\begin{array}{lll}\text { Parents owned home } & 0.62 & 0.49\end{array}$

$\begin{array}{lll}\text { Parents owned stocks } & 0.15 & 0.36\end{array}$

$\begin{array}{lll}\text { Parents had retirement savings } & 0.48 & 0.50\end{array}$

$\begin{array}{lll}\text { Parents unbanked } & 0.30 & 0.46\end{array}$

Peer Characteristics

High \% of peers planned to attend college $\quad 0.57 \quad 0.50$

High \% of peers attended church regularly $\quad \begin{array}{lll}0.25 & 0.44\end{array}$

High \% of peers smoked $\quad 0.28 \quad 0.45$

$N=7138$

Note: All statistics were calculated using sample weights. 